\title{
Best Practices and Lessons Learned in the Implementation of Global Framework for Climate Services-Adaptation Programme in Africa: Tanzania-Experience
}

\author{
Agnes Lawrence Kijazi ${ }^{1}$, Ladislaus Benedict Chang'a ${ }^{1 *}$, Wilbert Timiza Muruke ${ }^{2}$, \\ Mathew Masumbuko Ndaki², Mecklina Merchades Babyegeya3 ${ }^{3}$, Sudi Yasini Kisama4, \\ Omari Hamisi Juma ${ }^{5}$
}

\author{
${ }^{1}$ Tanzania Meteorological Authority, Dar es Salaam, Tanzania \\ ${ }^{2}$ Meteorological Cooperation Unit, Tanzania Meteorological Authority, Dar es Salaam, Tanzania \\ ${ }^{3}$ Agro-Meteorology Section, Tanzania Meteorological Authority, Dar es Salaam, Tanzania \\ ${ }^{4}$ Central Forecasting Office, Tanzania Meteorological Authority, Dar es Salaam, Tanzania \\ ${ }^{5}$ Climatology and Climate Change Section, Tanzania Meteorological Authority, Dar es Salaam, Tanzania \\ Email: ^ladislaus.changa@meteo.go.tz
}

How to cite this paper: Kijazi, A.L., Chang'a, L.B., Muruke, W.T., Ndaki, M.M., Babyegeya, M.M., Kisama, S.Y. and Juma, O.H. (2021) Best Practices and Lessons Learned in the Implementation of Global Framework for Climate Services-Adaptation Programme in Africa: Tanzania-Experience. Atmospheric and Climate Sciences, 11, 749-766. https://doi.org/10.4236/acs.2021.114044

Received: August 29, 2021

Accepted: October 26, 2021

Published: October 29, 2021

Copyright $\odot 2021$ by author(s) and Scientific Research Publishing Inc. This work is licensed under the Creative Commons Attribution International License (CC BY 4.0).

http://creativecommons.org/licenses/by/4.0/

\section{(c) (i) Open Access}

\begin{abstract}
This paper provides an analysis and a description of the best practices and lessons learned in the implementation of the Global Framework for Climate Services Adaptation Program in Africa (GFCS-APA) focusing on Tanzania country's activities. GFCS-APA was the first multi-agency initiative implemented under the Global Framework for Climate Services (GFCS) in two African countries, namely Tanzania and Malawi with funding from the Royal Government of Norway. In Tanzania, the programme was implemented in two phases from the year 2014 to 2021 in the three pilot districts of Kondoa, Longido and Kiteto located in Dodoma, Arusha and Manyara regions, respectively. The overarching goal of the programme was to enable better management of the risks caused by climate variability and change at all levels, from end-users to policy level, through development and incorporation of science-based climate information and prediction services into planning, policy and practice. The programme focused on bridging the gap between providers and users of climate information and products through development of user-driven climate services for food security, health and disaster risk reduction. This paper aimed to analyze lessons learned and best practices in the course of the implementation of the GFCS-APA phase I and II in Tanzania. A qualitative approach was employed to analyze the lessons learned and best practices, by extracting them and exploring further on their contribution to the enhancement of climate
\end{abstract}


services, as well as their applicability and potentiality for scaling out in other regions within Tanzania, and in other countries. The results indicate the identified best practices and lessons learned contributed significantly in enhancing climate services, particularly in understanding, availability, accessibility, utilization, ownership and sustainability of climate services among users (farmers and pastoralists) of various gender, as well as intermediaries and decision-makers. Results also indicate the lessons learned and the documented best practices could influence the effectiveness of climate services in other areas, to address existing challenges in access, uptake and sustainability of climate services. The best practices and lessons learned could be considered for integration in the future projects or operational activities in other regions within the country and other countries, particularly in the developing world, including SubSaharan Africa.

\section{Keywords}

GFCS-APA, Climate Variability, Climate Change, Climate Services, Best Practices, Lessons Learned

\section{Introduction}

Climate change is among the biggest challenges of the $21^{\text {st }}$ century affecting all socio-economic sectors [1] [2] [3] [4]. Communities in both rural and urban settings in various countries including in Tanzania, have been suffering from the impacts of climate variability and change including observed and projected increase in frequency and magnitude of extreme weather and climate events such as floods and droughts [4]-[11]. People from rural settings are particularly vulnerable to the impacts of climate variability and change due to the inability to recover from drought and flood events, thus contributing to higher levels of food insecurity [6]. The situations have further been aggravated by other external factors including some gaps and challenges in the provision of climate services that cause weak adaptive capacity. This calls for the provision of effective climate services that is easily accessible and timely scientific climate data and information to support the government, institutions and individuals to make informed decisions.

To address this challenge, there have been various initiatives by the World Meteorological Organization (WMO) in collaboration with other stakeholders in weather and climate services across the Globe. The initiatives are aimed at strengthening adaptive capacity to climate change by societies including enhancing climate services by increasing effectiveness in the provision and utilization of sciencebased climate services at various levels [6]. Considering the fact that weather and climate risks affect human activities including the implementation of various national policies, the provision of early warning information is critical in saving lives and reducing losses from disastrous hazard events such as drought, storms and floods [12] [13] [14] [15]. 
Among the initiatives undertaken by WMO and partners in Africa was the implementation of the Global Framework for Climate Services Adaptation Programme in Africa (GFCS-APA). GFCS-APA was the first multi-agency initiative implemented under the GFCS in two African countries of Tanzania and Malawi with funding by the Royal Government of Norway [6]. In Tanzania, the programme was implemented in two phases from the year 2014 to 2021 in the three pilot districts of Kondoa, Longido and Kiteto located in Dodoma, Arusha and Manyara regions, respectively. Implementation of the GFCS-APA in Tanzania was one example of the WMO initiatives to reduce vulnerability caused by the impact of climate change through the provision of effective climate services that enhances the resilience of vulnerable sectors and populations [6] [16].

The overarching goal of the programme was to enable better management of the risks of climate variability and change at all levels, through the development and incorporation of science-based climate information and prediction services into planning, policy and practice. The programme aimed to increase the resilience of those most vulnerable to the impacts of weather and climate-related hazards, such as droughts and flooding, and associated health risks, including malnutrition, cholera and malaria [6] [17]. It focused on bridging the gap between providers and users of climate information and products through the development of user-driven climate services for food security, health and disaster risk reduction. It also emphasized on user engagements and co-productions of climate services. The implementation of this programme had a number of lessons learned and best practices during the course of its implementation in Tanzania and lead to the key achievements in provision, dissemination and utilization of climate information and products.

The study aimed at identifying and analyzing lessons learned and best practices documented during the implementation of the GFCS-APA phase I and II in Tanzania. The study also focused on exploring the role and significance of the identified lessons learned and best practices in the development of climate services, and the potential for scaling out within and outside Tanzania.

\section{Description of the Study Area}

The study was conducted in Kiteto and Longido districts in Manyara and Arusha regions respectively (Figure 1 ). Kiteto district is a Semi-arid area, located between latitudes $4^{\circ} 31^{\prime}$ and $6^{\circ} 03^{\prime} \mathrm{S}$ and longitudes $36^{\circ} 15^{\prime}$ and $37^{\circ} 25^{\prime} \mathrm{E}$, and covering an area of 16,685 square kilometres, and with a population of about 244,669 people of which 120,233 are males and 124,436 are females [18]. Longido district is also a Semi-arid area, located between latitude $1^{\circ} 00^{\prime} \mathrm{S}$ and $3^{\circ} 00^{\prime} \mathrm{S}$, and longitudes $36^{\circ} 00^{\prime}$ and $37^{\circ} 30^{\prime} \mathrm{E}$, and covering an area of 7782 square kilometres, with a population of about 123,153 people of which 62,954 are females and 60,199 males [19].

The climate pattern of both Kiteto and Longido districts is characterized by bimodal rainfall regime (the short rains and long rains) with stronger spatial and 


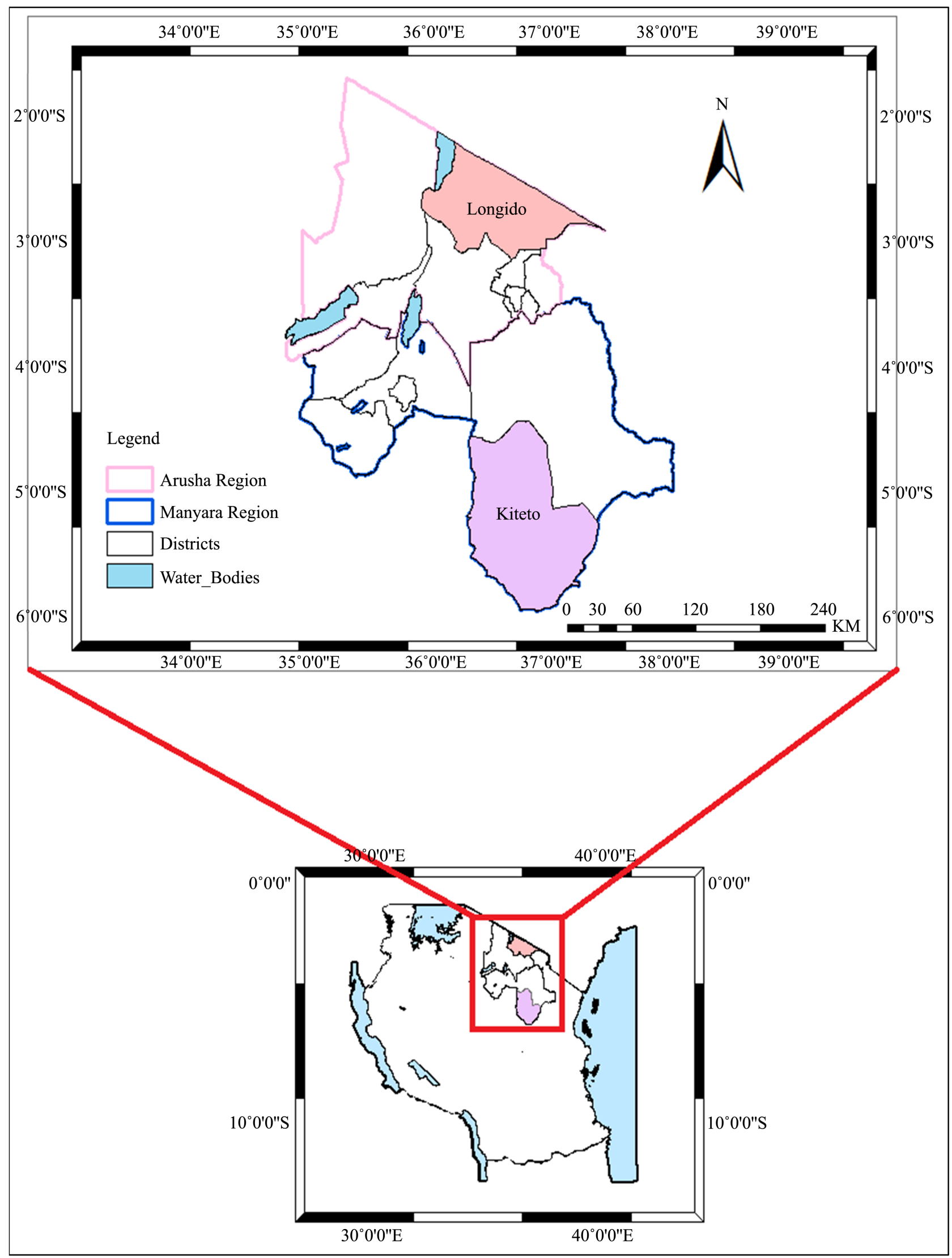

Figure 1. Map showing Kiteto and Longido districts. 
temporal variability. The short rain season begins in October and ends in December while the long rain season starts in March and ends in May. On the other hand, the southern part of Kiteto exhibit unimodal rainfall regime characterized by rains which peak from November to May [20].

Both Kiteto and Longido districts are frequently affected by climate variability and the associated weather and climate extremes, particularly droughts. Some of the severe droughts that affected the districts in the last two decades include the droughts of 2000, 2006, 2009 and 2016. The 2009 drought was the worst in record and led to severe food shortage, water scarcity and large migration of herders to other areas [21] [22] [23].

The main crops grown in Kiteto district are sorghum, sunflower, cotton, finger millet and cassava, while Longido is endowed with a variety of livestock; dairy cattle, beef cattle, sheep, pigs, goats, donkeys. Food crops grown in Longido district include horticultural crops, maize, beans, green beans and potatoes in high lands and lower land [19].

\section{Data Description}

This paper used secondary data related to the implementation of Global Framework for Climate Services Adaptation Programme in Africa (GFCS APA) in Tanzania and related information. The data used were mainly project reports and publications by GFCS APA implementing partners in Tanzania. Other secondary data used were publications related to GFCS programme, including the National Framework for Climate Services (NFCS), GFCS book, and other related publications about climate services in the pilot areas and related countries.

\section{Methodology}

A qualitative approach was employed to analyze the lessons learned and best practices. Best practices and lessons learned were extracted from reports of various activities implemented under GFCS-APA phase I and II. The contributions of the lessons learned and best practices in enhancement of climate services were explored through in-depth review of the reports, and other related publications about climate services in the pilot areas. Interview with key informants (District Agricultural and Livestock Officers) in the pilot areas was also conducted to validate the socio-economic benefits of the identified best practices. Based on the geographic nature and livelihoods of the majority in the pilot areas with the support from the literature, potential areas where the best practices and lessons learned could be out-scaled to support enhancement of climate services were identified.

\section{Results and Discussions on Best Practices and Lessons Learned}

\subsection{Best Practices}

Some of the best practices documented during the implementation of GFCS 
programme are described. The highlighted best practices focus on various categories of climate services value chain and formulation, and implementation of the National Framework for Climate Services. These include information sharing, user-engagement including training and awareness, and governance mechanism.

\subsubsection{Information Sharing Using Mobile Phones}

GFCS programme aimed at enhancing information dissemination to end users using various channels, and in a more accessible and cost-effective manner. The use of short mobile text messages (SMS) and voice services of mobile phones were preferred options among many end users. More than 42,500 farmers (end users) in the pilot project districts received weather and climate information via FarmSMS system (text message) or through Beep 4 weather system (voice message). The Beep 4 weather system provides access of weather and climate information to those who are unable to read text messages properly. Furthermore, for those who could not understand Swahili properly, the translation of climate information to Maasai language was done for enhanced understanding [6] [23].

\subsubsection{Dialogues between Providers and Users of Climate Services}

GFCS-APA implementation used dialogues platforms among stakeholders, especially between providers and users of climate services. It was an opportunity for climate service provider to understand user needs; it also assisted better understanding and dissemination of climate services provided by TMA. Various platforms for sustained dialogue between providers and users of climate services were established and strengthened. These include the platforms between TMA experts and Media communities three times a year during preparation of the seasonal climate outlook for Tanzania, platform between TMA experts and stakeholders from climate sensitive sectors including stakeholders from Agriculture, Livestock, Water, Energy, Health and Disaster Risk Reduction sectors. Other stakeholders involved include extensionist, civil societies, security agencies and Local government authorities.

\subsubsection{Use of Participatory Integrated Climate Services for Agriculture (PICSA) Tools in Designing and Executing Climate Service Programs}

PICSA involved agriculture extension officers working with groups of farmers/pastoralists ahead of each growing season. A participatory needs assessment studies ensured that, differing information needs across vulnerable groups were considered in the on-going co-production of climate information products and services and ensuring that were evaluated on an on-going basis to further refine the products over time. Agriculture extension officers worked closely with farmers and pastoralists; to analyse historical climate information; to choose crops, livestock and livelihood options that best suit to individual farmers' circumstances. The tool facilitated small scale farmers in the GFCS pilot areas to improve their resilience in the context of increasing climate variability and climate 
change manifested through decreasing rainfall patterns, shifting in rainfall seasonality and increasing temperature. The use of PICSA tool has enabled pastoralists to sustainably manage their livestock despite the changes in climatic conditions. Extension officers and NGO staffs were able to facilitate farmers and pastoralists to use complex information on historical climate, seasonal and short-term forecasts as well as crop, livestock and livelihood options in decision making leading to improved outputs. However, the tool needs to be translated into local languages for better understanding and enhanced uptake by the respective communities.

\subsubsection{Governance Mechanism Ensuring High Level Involvement of Government Machinery in Steering the Implementation of GFCS and Establishment of Multi-Institutional Technical Committee}

Project governance mechanism at national level is an important mechanism for smooth implementation of national projects and programmes. During GFCS implementation, National Steering Committee (NSC) and Project Delivery Team (PDT) were formed to governed smooth implementation of GFCS activities at national level. The NSC role was taken by the Tanzania Disaster Management Council (TADMAC) having the role of overseeing the implementation of GFCS and development of National Framework on Climate Services. It provided political support, sustainability, and platform to assess and measure project achievements. Whilst PDT was established as the technical committee with the role of coordinating and managing the implementation of program activities and was supported by GFCS desk officer and GFSC senior technical advisor.

\subsection{Lessons Learned}

\subsubsection{Comprehensive Stakeholders' Participation Is Critical for Project Ownership, Effective Implementation and Sustainability}

Successful implementation of the project requires strong collaboration and engagement among stakeholders. During project appraisal stage, focus should be on community needs through co-planning of project activities. Rural communities were not involved in the designing stage of the GFCS programme and as a result, some of the communities did not feel sense of ownership of the project interventions. It is important to ensure active involvement of the local communities from planning process to adequately and appropriately capture the specific climate services user needs and priorities to enhance utility and sustainability of the outputs and outcome. For example, the GFCS program rehabilitated the earth dam in Olpopong village, in Kiteto district to fulfil community priority and needs to improve water availability, even though it was not prioritized in the initial planning stages due to lack of involvement of the communities from Olpopong village in Kiteto district. Community priorities change with local circumstances; hence it is a good practice if the project initiates an innovation platform with flexibility and to have a co-planning component of project activities with local communities. 


\subsubsection{Enhanced Awareness and Effective Use of Climate Services Is a Key for Sustainable Management of Natural Resources}

Raising awareness about the challenges of climate change and the importance of mainstreaming climate services information and products in planning and implementation of various socio-economic sectors is critical for climate change adaptation and enhanced production and productivity in all sectors. Promoting rainwater harvesting technologies and enhanced adoption among local communities and Local government authorities contribute to addressing the emerging water shortage due to decreasing rainfall trend and increasing climate variability in some areas, the problem which has been attributed to climate change. The decreasing rainfall patterns and increasing temperature trend coupled with increasing frequency and intensity of extreme events are becoming widespread and consequential [5] [21] [24]. The dry spells are becoming more frequent and lengthy [21] [25].

\subsubsection{Establishing a Clear and Sustained Feedback Mechanism between Users and Providers of Climate Services Is Important for Improvement in Service Provision}

User feedback mechanism plays an important role in improving climate services. It helps climate service providers to understand the gaps, emerging needs and the challenges in the services provision and thus be able to adjust accordingly to improve efficiency and effectiveness. It enables the services provided to be more relevance and valuable. During the design and initial stages of implementation of the GFCS programme, there was no clear feedback mechanism, which also affected the uptake. However, this challenge was rectified in the course of the implementation of the project and in the establishment and implementation of the National Framework for Climate Services, whereby feedback mechanism was integrated in the process of preparation of seasonal climate outlooks, but also through administering of questionnaire through various national exhibitions such as agricultural exhibition annually held in August. It is a good practice to put in place feedback mechanism for monitoring and improvement of the programme activities.

\subsubsection{Increasing Demand of High-Resolution Climate Information}

The demand for high resolution climate information is increasing due to the challenges of climate change, but also due to increasing awareness about the importance of factoring in climate information and products in planning and implementation of various socio-economic sectors. Provision of high-resolution climate information that captures local climate features can only be achieved by expanding, enhancing and sustaining climate observation network. During the implementation of the programme, insufficient observation network in the pilot districts was a limiting factor for production of high-resolution climate information. Similarly, it has become increasingly difficult to recruit people to act as manual weather observers, and so installation of new technologies (automatic weather stations) can overcome shortfalls in human resources. 


\subsubsection{Timely, Appropriate, Adequate and Innovative Reporting Is Important for Successfully Implementation of the Programme}

Programme reporting is a key component in ensuring project objectives, output, outcome, challenges, best practices and lessons learned are well communicated and documented. Project implementers in Tanzania designed a clear template for reporting project progress on monthly and quarterly basis. The reports were presented and discussed at the technical committee (PDT) meetings, which were convened quarterly. The deliberation of the progress reports in implementation of the individual project activities enabled members and partners to have common understanding about the progress and was instrumental in identifying the bottlenecks and also facilitated in avoiding duplication and ensuring synergies and coherence in the implementation of the GFCS activities. The innovative part of the reporting was provision of needs and mechanism for capturing segregated gender perspectives in the implementation of all GFCS activities. It is also important to ensure that, key components of the project logframe including the outcome, outputs and indicators are reflected in the designing of the reporting mechanism and template.

\subsubsection{Gender Mainstreaming Is a Key towards Successful Program Implementation}

The effects of weather and climate are not gender neutral. Women and men are frequently and differently affected by weather and climate impacts. During GFCS implementation, gender aspects were reflected in project activities, with women participation comparatively fair. There was an observation that some women were not free to talk in front of men due to cultural norms. Women voices were only heard when they were encouraged to talk, as well as when providing them with gender specific needs. GFCS programme emphasized reflection on gender perspective during implementation and reporting, and this was the reason behind formation of women exclusive community listening groups for community radio programmes and "Her Voice on Air" climate change radio segments. The female exclusive community listening groups and Her Voice on Air radio segments were very successful in ensuring gender issues particularly those of women are aired and adequately addressed during the implementation of the project.

\subsection{Contribution of the Lessons Learned and Best Practices in Enhancement of Climate Services in the Respective Areas and Sectors}

The contribution of the best practices and lessons learned in enhancement of climate services in Longido and Kiteto district as well as in the priority sectors are as outlined below:

\subsubsection{Contribution of Best Practices}

1) The use of mobile phones through FarmSMS system and Beep 4 weather for climate information sharing contributed in enhancing efficiency and effec- 
tiveness in dissemination of climate information in remote areas, hence there was improved access to climate information that facilitated planning of socio-economic activities and decision making due to timely dissemination of information and availability of feedback and interactive mechanism.

2) The use of community radios contributed to improved dissemination and awareness to the surrounding communities, particularly on the application on weather information. The knowledge acquired through the project, supported farmers and pastoralists in planning and making informed decisions by making use of locally relevant advisories that were provided by agriculture and livestock extension officers through special radio programmes. Farmers and pastoralists could further discuss the advisories in special listener groups of men and women, with their local extension officers and have a consensus on appropriate actions to be taken. One of the community radio that was used in the programme was Farm Radio International (FRI).

3) The use of local language in communicating weather and climate information contributed in effective use of weather information. Most of the farmers and pastoralists in the study area were much more conversant and comfortable to use their local tribal language as compared to Swahili and English. The translation of climate information to their local language (Maasai) increased understanding as well as ownership of the information.

4) Dialogue platforms on climate services facilitated cross learning between providers and users of climate services in terms of the existing challenges and opportunities, thus paving the way for effective implementation of the GFCS project, its sustainability as well as effective implementation of future projects.

5) The use of District Health Information System version 2 (DHIS2) had a significant contribution in health early warning services as it integrated directly the weather and climate data with health information and thus increased resilience of climate change impacts to health sector.

6) The governance mechanism of GFCS project contributed to successful implementation of the GFCS phase I \& II. Involvement of Tanzania Disaster Management Council (TADMAC) as the National Steering Committee (NSC) and the Project Delivery Team (PDT) contributed in effective implementation of the project. The NSC provided political support for sustainability of the project, national ownership and coordination of the development and implementation of the National Framework for Climate Services (NFCS).

The details about the best practices and their contribution in enhancing climate services in the localities are stipulated in Table 1.

\subsubsection{Contribution of Lessons Learned}

1) Involvement of local project beneficiaries in the design of activities helped to address local needs, project ownership and sustainability. An example was the decision to come up with an activity on rehabilitation of earth dam which was through involvement of local people. This activity was not part of the initial project plan but it was included and implemented after being raised as a local 
Table 1. Contribution of best practices in enhancement of climate services.

\begin{tabular}{lll}
\hline Best practice $\quad$ objective & Findings and achievements & $\begin{array}{c}\text { Contribution in } \\
\text { enhancement of climate services }\end{array}$
\end{tabular}

1) The use of mobile phone both voice and SMS for climate information sharing

2) The use of community Radio for dissemination of weather and climate information
3) Translation of weather information to local language (e.g. Maasai language)

\section{4) Existing dialogues between climate service providers and users}

5) Encouragement of young generation to be involved in the discussion of climate change impacts
To increase the number of climate information users through the use of FarmSMS, Beep 4 weather and Uliza Poll

To disseminate weather and climate information timely and in a user-friendly way a) 15,883 farmers and pastoralists from 30 regions were registered in FarmSMS system (up to January 2020);

b) SMS and village communicators were found to be potential channels to reach communities since ownership of cell phones is higher than radio in Kiteto and Longido; c) Beep 4 weather and Uliza Poll act as the alternative platforms of receiving climate information in voice messages for those who face difficulties in understanding and interpretation of weather information.

a) 3 community radio stations were used to disseminate climate information (Mwangaza Fm in Kiteto, Irangi Fm in Kondoa, and Olkonorei radio in Longido) and these radios were found to be the appropriate channel for dissemination of climate information;

b) 60 community listeners group were created to listen climate information together from the radio; c) More than 460 farmers and pastoralists from 8 villages were reached through community radio;

d) Solar-powered MP3 radio was given to farmers in the area where the radio was not covered.

To increase awareness of weather information to users who are not family with English and Swahili languages

To establish compromises and agreements between provider and user to meet the needs of users

To involve the students from primary and secondary schools in capacity building and using of climate information as well as adapting to climate change a) Text messages from FarmSMS were translated to Maasai language in the respective areas; was announced in the community Radio in Maasai language.

Farmers and Pastoralists from 9 villages (Kaskazini A, Kibaya, Olmolog, Ralang'wa, Irkaswa, Kamwanga, Kiserian, Longido and Kimokouwa) participated in dialogue meetings.

a) Nine (9) secondary schools 3 primary were visited and student were participated in weather and climate information awareness;

b) Five (5) environmental clubs were established with 25 - 35 members in the schools visited. The clubs were registered by Tanzania Red Cross Society (TRCS) as Red Cross branch at the grass root level. b) The weather and climate information
FarmSMS has tremendously increased the number of climate information users by $60 \%$ and hence timely dissemination of information and therefore improved the feedback mechanism.

Beep 4 weather and Uliza Poll became the best platforms for users to understand the climate information since they were free to ask any question and receive answer timely.

Community radios helped to increase awareness of weather information because people were able to discuss in groups and this helped to have a unique correct decision for their agriculture and livestock activities.

Better outcome of using community radio over the area made TMA to increase the number of community radios from 3 to 52 which currently receive and disseminate weather information over the country. Generally, these radio programs have contributed in enhancing the capacity of communities and promote accessibility of climate information and advisories.

Most of the farmers and pastoralist in the study area preferred their local tribal language as they faced difficulties in understanding Swahili and English languages. The translation of climate information to their local language (Maasai) increased understanding as well as they felt like the information was special for them.

Dialogues were a platform for climate services users and providers to learn about challenges and opportunities, thus paving the way for effective implementation of GFCS as well as other future projects.

Sensitization of young generation on weather and climate information as well as climate change impacts. Students were involved in discussion about planting trees, conservation of natural resources which can contribute to climate change resilience over their areas. 


\begin{tabular}{|c|c|c|c|}
\hline $\begin{array}{l}\text { 6) Involvement of } \\
\text { other related } \\
\text { sectors in the } \\
\text { implementation } \\
\text { of the project }\end{array}$ & $\begin{array}{l}\text { a) To improve the } \\
\text { weather and climate } \\
\text { early warning system } \\
\text { b) To involve other } \\
\text { sectors to be part of } \\
\text { climate service } \\
\text { designing process } \\
\text { as well as to } \\
\text { integrate user needs }\end{array}$ & $\begin{array}{l}\text { a) Designation of TADMAC as the } \\
\text { National Steering Committee; } \\
\text { b) Development of DHTS2 } \\
\text { (health software) dashboard for } \\
\text { integration of climate weather data; } \\
\text { c) Higher level education institution, } \\
\text { health and agricultural institution were } \\
\text { involved in decision making; } \\
\text { d) } 99 \% \text { of agricultural extension officers } \\
\text { in Longido and Kiteto districts were } \\
\text { trained on PICSA approach; } \\
\text { e) } 68 \text { District and Regional } \\
\text { Environmental Health and Medical } \\
\text { Officers were trained on the use of } \\
\text { weather and climate information. }\end{array}$ & $\begin{array}{l}\text { DHTS2 had a significant contribution in } \\
\text { health early warning system by directly } \\
\text { integrating weather and climate data, } \\
\text { which increased resilience of climate } \\
\text { change impacts to health sector. } \\
\text { Also involvement of TADMAC, } \\
\text { Ministry of Health as well as the Ministry } \\
\text { of Agriculture staff in weather and climate } \\
\text { information discussion became the best way } \\
\text { of having representative in many sectors } \\
\text { and hence became a long-term strategy } \\
\text { in adaptation of climate change impacts. }\end{array}$ \\
\hline
\end{tabular}

community requirement and it became a remarkable achievement that contributed in ensuring availability of water for agro-pastoral activities during dry seasons over the area.

2) The use of climate services in natural resources management (e.g water resources management in Olpopong village) helped communities to respond to poor rainfall distribution and low water availability through rainwater harvesting using the rehabilitated earth dam. The harvested water ensured availability of water for agro-pastoral activities during dry seasons over the area. Therefore, rainwater harvesting is the key in areas, which are strongly impacted by climate variability and change.

3) Feedback gathered from users through user interface platforms such as "Uliza Polls", Beep 4 weather, community radios, meetings and workshops contributed considerably in enhancing climate services in Longido and Kiteto districts. The feedback was used as input in improvement in the generation and packaging of the products and services provided by TMA. For instance, through user feedback, a need to increase rainfall observation stations was raised whereby TMA acted on the need by installing six rain gauges in the two districts. Also, the need for translating weather information into Maasai language came up from user feedback.

4) Mainstreaming of gender aspects in the implementation of GFCS APA made climate services to be effective. Through the gender related "Community Listener Groups", climate information priorities for men and women were identified whereby the first priority for men was the start dates of the rainy season as an indication of availability of water and pasture for livestock, as well as good soil moisture to support farming activities. On the other hand, the first priority for women was amount of rainfall as indication of sufficient water availability. Moreover, following the observation that some women were not free to talk in front of men due to cultural norms, "(60) Community Listener Groups" for community radio programmes were formed of which thirty-eight (38) groups were "Women Exclusive Community Listener Groups". In addition, "Her Voice on 
Air" climate change radio segment was formed to encourage women to express themselves.

5) Enhancing ground observation network is the key in the provision of highresolution climate services. Availability of rainfall stations in the pilot districts helped to address the need of downscaled forecasts by communities. The need for more stations came up in the course of implementation of the project, as the available stations are inadequate to represent the various agro-ecological zones. However, the stations should be automatic to ensure a smooth flow of data and avoid the cost implication of manual observers.

6) Through baseline survey, TMA was able to identify priority activities, which were proposed by users. Among the survey findings which contributed in enhancing of climate services provided by TMA include gender preferences in climate services and reliance of farmers and pastoralists in Indigenous Knowledge (IK) which necessitated the need for integration of IK with scientific forecast that will enhance area specific climate information.

The details about the lesson learned and their contribution in enhancing climate services in the localities are stipulated in Table 2.

\subsection{Applicability of the Best Practices and Lessons Learned and Potential for Scaling Out to Other Countries}

Studies show that users of climate services in many countries, particularly in Africa have limited access and uptake of relevant climate information [23] have indicated that barriers to uptake of climate services are attributed to how the knowledge is conceptualized, framed and en-countered. According to [26], one of the primary barriers is to view the user as lacking climate knowledge relevant for services and applications. [26] views this as a "linear mode of knowledge production" or "deficit model" which focuses on the notion that all that is required is to fill up the deficit or knowledge gap between providers of climate information and end users. This barrier to uptake of climate services has also been narrated by [27]. In addition to access and uptake, studies have indicated that most projects face the challenge of sustainability and knowledge uptake [28].

Since the challenges presented by the authors seem to be more or less the same as the ones that existed in Longido and Kiteto districts, the best practices and lessons learned provided in this paper can be applied and be of benefit to other countries within and outside Africa, especially in the tropical areas to support effective climate services and resilience to climate change.

\section{Conclusion}

Capturing, documenting and sharing the best practices and lessons learned in the implementation of the GFCS projects and other climate, water and environmental related projects and initiatives is critical for enhancing cross-learning and ensuring the best use of available resources and maximizing the benefits of the intervention across the globe. The best practices and lessons learned shared from the implementation of the GFCS programme in Tanzania, with an emphasis 
Table 2. Contribution of lessons learned in enhancement of climate services.

\begin{tabular}{|c|c|c|c|}
\hline Lesson learned & $\begin{array}{l}\text { The purpose/objective } \\
\text { of best practices } \\
\text { and lesson leant }\end{array}$ & $\begin{array}{c}\text { Findings during } \\
\text { implementation lesson leant }\end{array}$ & $\begin{array}{l}\text { Contribution in enhancement } \\
\text { of climate services to } \\
\text { respective areas and sectors. }\end{array}$ \\
\hline
\end{tabular}

$\begin{array}{ll}\text { 1) Having in place a } & \text { To ensure smooth } \\ \text { GFCS governance } & \text { running of the } \\ \text { mechanism at } & \text { project with } \\ \text { national level } & \text { best results }\end{array}$

2) Baseline survey to identify weather and climate information user needs

3) Gender mainstreaming is key towards successful program implementation and women to be
To encourage both men involved in the use of weather and climate services in planning and decision making in their socio-economic activities
4) Feedback
mechanism
between users and providers of climate services is important

To find out the primary ways on their current climate change situation as well as how the users get, use and their priorities of weather and climate products for their decisions a) Good governance mechanism ensured all activities planned to be implemented timely; b) Successful implementation of the programme.

a) Drought was found to be the most significant threat to agriculture followed by pest and diseases; b) At least $80 \%$ of the farmers and pastoralists relied on indigenous knowledge and personal experience to make farm decisions; c) Less than $50 \%$ of households acknowledged receiving climate information, with limited use of climate information to make farm decisions; d) Longido and Kiteto lived with climate change impacts and had developed local adaptive strategies;

e) Rainfall onsets, expected amount of rainfall over the season, end date of the rainy season, number of raindays and probability of extreme events were identified as the preferred climate information by farmers.

a) Men and women were interviewed separately to identify their individual requirements;

b) Gender was considered in creation of community listeners groups. The groups were 60 in total, of which 38 were women groups while 22 were men groups;

c) Environmental clubs were created in schools containing equal number of female and male students;

d) Formation of "Women Exclusive Community Listening Groups" for community radio program and

"Her Voice on Air" climate change radio segment following an observation that some women were not free to talk in front of men due to cultural norms.

a) Uliza poll and Beep 4 weather became the best platform for collection of feedback from the farmers and pastoralists;

b) FarmSMS system improved feedback mechanism between service provider, intermediaries and user of climate services in 9 villages.
The governance of GFCS project was good and resulted to successful implementation of GFCS phase I \& II and hence similar approach may be used in the implementation of other projects.

Through baseline survey provider of climate services was able to identify current situation of the users include the local climate change impacts which act as input in preparation of climate products.
Through the gender related

"Community Listener Groups" climate information priorities for men and women were identified, that enhanced the skills of providers to meet or exceeds user needs. For example the first priority for men was the start dates of seasonal rainfall while women's first priority was amount of rainfall.

Uliza Polls, Beep 4 weather, community radios, meetings and workshops contributed significantly in collection of feedback from the users.

The feedbacks were used as input in improvement of the products and services provided by TMA and hence more than 44,000 end users were reached and received highly improved climate services. 


\begin{tabular}{|c|c|c|c|}
\hline $\begin{array}{l}\text { 5) Stakeholders' } \\
\text { participation is critical } \\
\text { for project ownership } \\
\text { and sustainability }\end{array}$ & $\begin{array}{l}\text { To ensure ownership } \\
\text { of the project and } \\
\text { sustainable achievements }\end{array}$ & $\begin{array}{l}\text { Rehabilitation of earth dam in Olpopong } \\
\text { village, Kiteto district which involved } \\
\text { planting of trees, construction of water } \\
\text { reservoirs, and procurement of new gate } \\
\text { valve for controlling water flows. }\end{array}$ & $\begin{array}{l}\text { Rehabilitation of earth dam was not part } \\
\text { of the project plan but it was implementing } \\
\text { due to stakeholders requirements and } \\
\text { hence it became the remarkable } \\
\text { achievement that contributed in ensuring } \\
\text { availability of water for agro-pastoral } \\
\text { activities during dry seasons over the area. }\end{array}$ \\
\hline $\begin{array}{l}\text { 6) The need for } \\
\text { adequate climate } \\
\text { observation network } \\
\text { to enhance } \\
\text { production of } \\
\text { high-resolution } \\
\text { climate information }\end{array}$ & $\begin{array}{l}\text { To get downscaled } \\
\text { weather and climate } \\
\text { information with a high } \\
\text { resolution for local areas }\end{array}$ & $\begin{array}{l}\text { a) } 6 \text { Rain gauges were installed in } \\
\text { Tingatinga and Dosidosi villages. } \\
\text { b) Plan for enhancement of weather } \\
\text { reporting using automatic weather } \\
\text { stations; } \\
\text { c) Temperature Rainfall data from } \\
9 \text { regions were digitized and entered } \\
\text { in TMA Climate data base } \\
\text { management system (CLIDATA). }\end{array}$ & $\begin{array}{l}\text { Rain gauges installed contributed to } \\
\text { get initial condition data in } \\
\text { preparation of high-resolution } \\
\text { weather forecast over the area; } \\
\text { Most of the historical temperature } \\
\text { and rainfall data were in paper forms, } \\
\text { but through the digitization, the data } \\
\text { are current in CLIDATA in electronic } \\
\text { form that enable easy analysis and } \\
\text { hence enabled to get a correct } \\
\text { climatology baseline that } \\
\text { contributed in the resilience to } \\
\text { climate change impacts. }\end{array}$ \\
\hline
\end{tabular}

on Longido and Kiteto provides opportunities for enhancing efficiency and effectiveness and for accelerating the implementation of similar initiatives, particularly in countries or regions with a similar setup and similar geographic and climatic characteristics to Longido and Kiteto districts. The practices demonstrated to be highly instrumental in enhancing climate services as they contributed significantly in enhancing awareness and understanding, availability, accessibility, utilization, ownership and sustainability of climate services among users (farmers and pastoralists) of various genders, as well as intermediaries and decisionmakers.

\section{Recommendations}

Since the findings indicate that some of the challenges that existed in Longido and Kiteto districts also exist in other areas within and outside Tanzania, it is recommended for the documented best practices and lessons learned to be considered in planning and implementation of ongoing and future projects or operational activities in other regions within Tanzania and in other countries, with similar challenges. Potential areas for out-scaling within Tanzania could include Shinyanga, Simiyu, Singida, Dodoma and parts of the Mwanza regions. Areas outside Tanzania could include countries with aridity to semi-aridity nature, including Sub-Saharan Africa.

\section{Acknowledgements}

The authors would like to acknowledge the financial and technical support by WMO and the Royal Government of Norway that facilitated the preparation of this paper through the GFCS-APA programme. We would like also to acknowledge the GFCS-APA implementation partners, authors of reports, publications 
and other documentation related to GFCS APA implementation in Tanzania, including WMO, Norwegian Capacity/Norwegian Refugee Centre (NORCAP/NRC), TMA, Ministry of Agriculture (MoA), Ministry of Health, Community Development, Gender, Elderly and Children (MoHCDGEC), the University of Dar es Salaam, CGIAR Research Programme on Climate Change, Agriculture and Food Security (CCAF), Tanzania Red Cross (TRC), the World Food Programme (WFPTanzania), and the World Health Organization (WHO-Tanzania). We also thank colleagues from the TMA for fruitful discussion and recommendations that helped to improve this article. Lastly, but not least, the authors extend their gratitude to officials and experts at Kiteto and Longido district councils, and pastoralists and farmers for their support, particularly in validating the information presented in this paper.

\section{Conflicts of Interest}

The authors declare no conflicts of interest regarding the publication of this paper.

\section{References}

[1] IPCC (2007) Climate Change 2007: Summary for Policymakers.

[2] IPCC (2018) Global Warming of $1.5^{\circ} \mathrm{C}$ : An IPCC Special Report on the Impacts of Global Warming of $1.5^{\circ} \mathrm{C}$ above Pre-Industrial Levels and Related Global Greenhouse Gas Emission Pathways, in the Context of Strengthening the Global Response to Eradicate Poverty.

[3] IPCC (2020) The Ocean and Cryosphere in a Changing Climate.

[4] Shukla, P.R., Skea, J., Slade, R., Diemen, R., van Haughey, E., Malley, J., Pathak, M. and Pereira, J.P. (2019) IPCC Special Report on Climate Change, Desertification, Land Degradation, Sustainable Land Management, Food Security, and Greenhouse Gas Fluxes in Terrestrial Ecosystem: Technical Summary.

[5] Chang'a, L.B., Kijazi, A.L., Luhunga, P.M., Ng'ongolo, H.K. and Mtongor, H.I. (2017) Spatial and Temporal Analysis of Rainfall and Temperature Extreme Indices in Tanzania. Atmospheric and Climate Sciences, 7, 525-539. https://doi.org/10.4236/acs.2017.74038

[6] Hansen, J., Fara, K., Milliken, K., Boyce, C., Chang'a, L.B. and Allis, E. (2018) Strengthening Climate Services for the Food Security Sector. WMO Bulletin, 67, 20-26.

[7] IPCC (2012) Summary for Policymakers: Managing the Risks of Extreme Events and Disasters to Advance Climate Change Adaptation.

[8] Mkonda, M.Y. (2015) Vulnerability of Climate Change and Adaptation Strategies on Agriculture: The Case of Morogoro Municipalities, Tanzania. Global Advanced Research Journal of Agricultural Science, 4, 725-734.

[9] Mtongori, H., Stordal, F., Benestad, R., Mourice, S., Pereira-Flores, M. and Justino, F. (2015) Impacts of Climate and Farming Management on Maize Yield in Southerntanzania. African Crop Science Journal, 23, 399-417. https://doi.org/10.4314/acsj.v23i4.9

[10] Murray, V. and Ebi, K.L. (2012) IPCC Special Report on Managing the Risks of Extreme Events and Disasters to Advance Climate Change Adaptation (SREX). Journal of Epidemiology and Community Health, 66, 759-760. 
https://doi.org/10.1136/jech-2012-201045

[11] Nyenzi, B. and Lefale, P.F. (2006) El Niño Southern Oscillation (ENSQ) and Global Warming. Advances in Geosciences, 6, 95-101.

https://doi.org/10.5194/adgeo-6-95-2006

[12] Ame, H.K., Kijazi, A.L., Changa, L.B., Mafuru, K.B., Ngwali, M.K., Faki, M.M., Hmad, A.O. and Miraji, M.K. (2021) Rainfall Variability over Tanzania during October to December and Its Association with Sea Surface Temperature (SST). Atmospheric and Climate Sciences, 11, 324-341. https://doi.org/10.4236/acs.2021.112019

[13] Anande, D.M. and Luhunga, P.M. (2019) Assessment of Socio-Economic Impacts of the December 2011 Flood Event in Dar es Salaam, Tanzania. Atmospheric and Climate Sciences, 9, 421-437. https://doi.org/10.4236/acs.2019.93029

[14] Chang'a, L.B., Kijazi, A.L., Mafuru, K.B., Kondowe, A.L., Osima, S.E., Mtongori, H.I., Ng'ongolo, H.K., Juma, O.H. and Michael, E. (2020) Assessment of the Evolution and Socio-Economic Impacts of Extreme Rainfall Events in October 2019 over the East Africa. Atmospheric and Climate Sciences, 10, 319-338. https://doi.org/10.4236/acs.2020.103018

[15] Chang'a, L.B., Benedict, L., Kijazi, A.L., Mafuru, K.B., Nying'uro, P.A., Ssemujju, M., Deus, B., Kondowe, A.L., Yonah, I.B., Ngwali, M., Kisama, S.Y., Aimable, G., Sebaziga, J.N. and Mukamana, B. (2020) Understanding the Evolution and Socio-Economic Impacts of the Extreme Rainfall Events in March-May 2017 to 2020 in East Africa. Atmospheric and Climate Sciences, 10, 553-572. https://doi.org/10.4236/acs.2020.104029

[16] Luhunga, P.M., Kidebwana, E.T., Kijazi, A.L., Chang'a, L.B., Ng'ongolo, H. and Kondowe, A. (2019) Evaluation of the Performance of ENACTS MAP-ROOM Products over Tanzania. Atmospheric and Climate Sciences, 9, 202-212. https://doi.org/10.4236/acs.2019.92014

[17] Luhunga, P., Kidebwana, E.T., Kijazi, A., Chang'a, L.B., Ng'ongolo, H., Merchades, M. and Levira, P. (2019) The Contribution of the Global Framework for Climate Services Adaptation Programme in Africa (GFCS APA) in National Adaptation Plan (NAP) Process for Tanzania. Atmospheric and Climate Sciences, 9, 650-661. https://doi.org/10.4236/acs.2019.94040

[18] Jamhuri ya Muungano wa Tanzania Ofisi ya Rais Tawala za Mikoa na Serikali za Mitaa: Halmashauri ya Wilaya ya Kiteto. http://www.kitetodc.go.tz/

[19] Jamhuri ya Muungano wa Tanzania Ofisi ya Rais Tawala za Mikoa na Serikali za Mitaa Halmashauri ya Wilaya ya Longido. http://www.longidodc.go.tz/

[20] Zorita, E. and Tilya, F.F. (2002) Rainfall Variability in Northern Tanzania in the MarchMay Season (Long Rains) and Its Links to Large-Scale Climate Forcing. Climate Research, 20, 31-40. https://doi.org/10.3354/cr020031

[21] Kijazi, A.L. and Reason, C.J.C. (2009) Analysis of the 1998 to 2005 Drought over the Northeastern Highlands of Tanzania. Climate Research, 38, 209-223. https://doi.org/10.3354/cr00784

[22] Kijazi, A.L. and Reason, C.J.C. (2012) Intra-Seasonal Variability over the Northeastern Highlands of Tanzania. International Journal of Climatology, 32, 874-887. https://doi.org/10.1002/joc.2315

[23] West, J.J., Meaghan, D.E. and Yanda, P.Z. (2018) Evaluating User Satisfaction with Climate Services in Tanzania 2014-2016: Summary Report to the Global Framework for Climate Services Adaptation Programme in Africa. Center for International Climate Research.

[24] Chang'a, L.B., Japheth, L.P., Kijazi, A.L., Zobanya, E.H., Muhoma, L.F., Mliwa, M.A. and Chobo, J.S. (2021) Trends of Temperature Extreme Indices over Arusha and 
Kilimanjaro Regions in Tanzania. Atmospheric and Climate Sciences, 11, 520-534. https://doi.org/10.4236/acs.2021.113031.

[25] Han, F., Cook, K.H. and Vizy, E.K. (2019) Changes in Intense Rainfall Events and Dry Periods across Africa in the Twenty-First Century. Climate Dynamics, 53, 2757-2777. https://doi.org/10.1007/s00382-019-04653-Z.

[26] https://www.slideshare.net/cgiarclimate/arame-tall-2013-climate-services-lessons-fr om-africa-south-asia

[27] Vogel, C. and O’Brien, K. (2006) Who Can Eat Information? Examining the Effectiveness of Seasonal Climate Forecasts and Regional Climate Risk-Management Strategies. Climate Research, 33, 111-122. https://doi.org/10.3354/cr033111

[28] Dilling, L. and Lemos, M.C. (2011) Creating Usable Science: Opportunities and Constraints for Climate Knowledge Use and Their Implications for Science Policy. Global Environmental Change, 21, 680-689.

https://doi.org/10.1016/j.gloenvcha.2010.11.006 